\title{
POWER OUTPUT OF PERICARDIUM-LINED SKELETAL MUSCLE VENTRICLES, LEFT VENTRICULAR APEX TO AORTA CONFIGURATION: UP TO EGHT MONTHS IN CIRCULATION
}

Gregory A. Thomas, MD

Frank A. Baciewicz, Jr, MD

Robert L. Hammond

Kevin A. Greer, MD

Hurien Lu, MD

Steven Bastion, MS

Parmod Jindal, MD

Larry W. Stephenson, MD
Objective: The purpose of this experiment was to evaluate the potential for a skeletal muscle ventricle connected to the circulation between the left ventricle and the aorta to provide effective, long-term cardiac assist. Methods: Skeletal muscle ventricles were constructed from the latissimus muscle in 10 dogs. After conditioning, the skeletal muscle ventricles were connected to the left ventricle and the aorta with 2 valved conduits. The skeletal muscle ventricle was programmed to contract during diastole. Results: At time of implantation, skeletal muscle ventricles stimulated at $33 \mathrm{~Hz}$ and in a 1:2 ratio with the heart significantly decreased left ventricular work by $56 \%(P<.01)$ and at $50 \mathrm{~Hz}$ by $65 \%(P<.01)$. At a $1: 2$ ratio, the power output of the skeletal muscle ventricles was $59 \%$ of left ventricular power output at $33 \mathrm{~Hz}(P<.01)$ and $93 \%$ at $50 \mathrm{~Hz}(P<.01)$. Animals survived 7, 11, 16, 17, 72, 99, 115, 214, and 249 days. Three deaths were directly related to the skeletal muscle ventricle. One animal is alive at 228 days. In the animal that survived 249 days, skeletal muscle ventricle power output at 8 months with a $33 \mathrm{~Hz}$ stimulation frequency and a 1:2 contraction ratio was $57 \%$ of left ventricular power output and $82 \%$ at $50 \mathrm{~Hz}$. At a 1:1 ratio, skeletal muscle ventricle power output was $97 \%$ and $173 \%$ of the left ventricle at 33 and $50 \mathrm{~Hz}$, respectively. Conclusions: Left ventricular assist with a skeletal muscle ventricle connected between the left ventricle and the aorta is the most hemodynamically effective configuration we have tested and can maintain significant power output up to 8 months. (J Thorac Cardiovasc Surg 1998;116:1029-42)
W have studied thc use of skeletal muscle for cardiac assist by constructing muscular pouches, which we term skeletal muscle ventricles (SMVs). These SMVs have been connected to the circulation in a variety of ways for both left and right heart assist. ${ }^{1-3}$ When they were attached directly to the descending thoracic aorta and stimulated as aortic counterpulsators, we demonstrated that SMVs can pump blood chronically in the circulation, providing effective augmentation of diastolic blood pressure in a manner similar to the intra-

From the Division of Cardiothoracic Surgery, Department of Surgery, Wayne State University, Detroit, Mich.

Supported by National Institutes of Health grant HL34778.

Read at the Seventy-eighth Annual Meeting of The American Association for Thoracic Surgery, Boston, Mass, May 3-6, 1998.

Received for publication May 7, 1998; revisions requested June 3, 1998; revisions received July 31, 1998; accepted for publication Aug 5, 1998.

Address for reprints: Frank A. Baciewicz, Jr, MD, Suite 2102 Harper Professional Bldg, 3990 John R St, Detroit, MI 48201-2097.

Copyright $@ 1998$ by Mosby, Inc.

0022-5223/98 \$5.00+ $0 \quad \mathbf{1 2 / 6 / 9 3 6 1 4}$ aortic balloon pump. ${ }^{4}$ In 1 animal, an SMV lined with autogenous pericardium functioned continuously for over 4 years in circulation.

In acute studies, the most effective configuration for skeletal muscle hemodynamic assist that we have tested has been an SMV attached from the left ventricular (LV) apex to the aorta. ${ }^{5}$ In a recent study ${ }^{6}$ with this configuration, the longest survival we obtained was 11 weeks in 1 animal, with the others surviving only 10 to 14 days. Because the addition of a pericardial lining to the inner layer of the SMV was important in establishing the aortic counterpulsator model as a reproducible chronic model, the SMVs in our study were lined with autogenous pericardium. The purpose of this study was to develop pericardium-lined SMVs in a LV apex-to-aorta configuration as a chronic model for cardiac assist and to document hemodynamic performance over time.

\section{Materials and methods}

SMV construction and conditioning. Pericardium-lined SMVs were constructed in 10 mongrel dogs, weighing between 16 and $22 \mathrm{~kg}$, by a technique that has previously been 


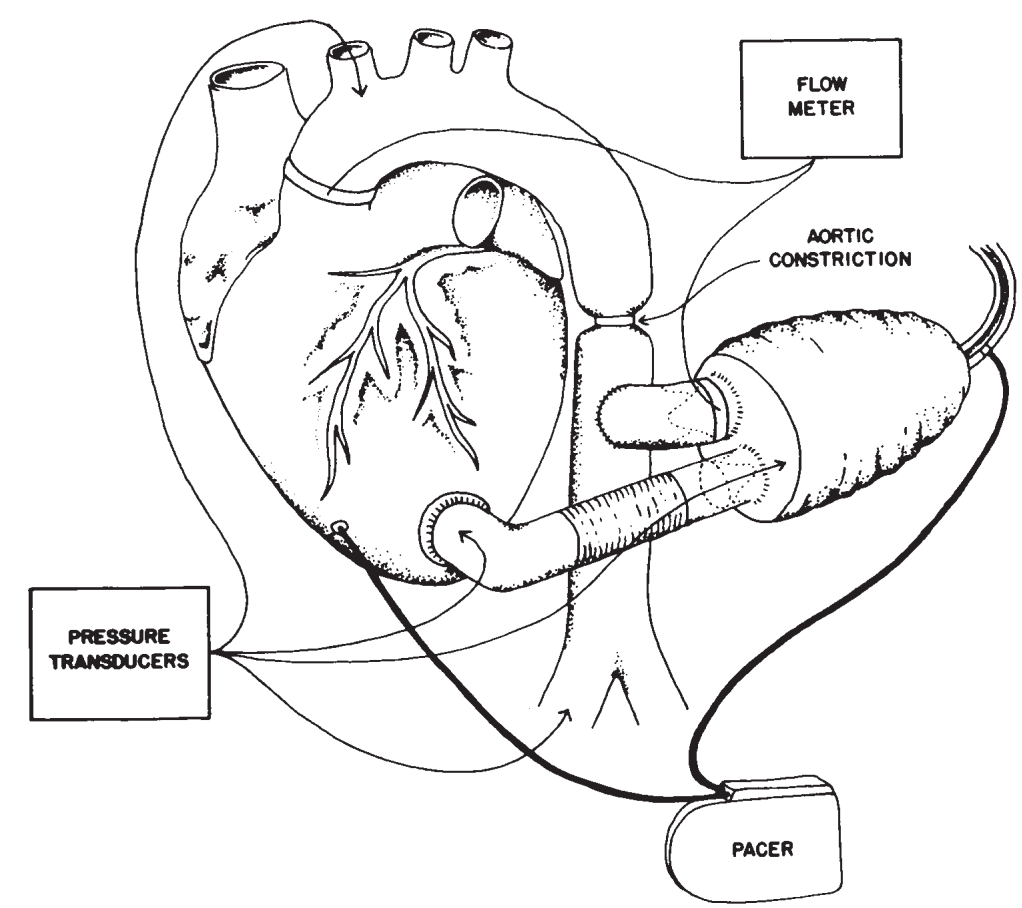

Fig 1. SMV is connected to the circulation between the LV apex and descending aorta with 2 valved conduits. A constriction was created proximal to the SMV-aortic anastomosis. Pressure was monitored in the left ventricle, SMV, and femoral and carotid arteries. Flow was measured at the aortic root and in the SMV efferent conduit.

described. ${ }^{7}$ All animals underwent operation in accordance with the "Guide for the Care and Use of Laboratory Animals" published by the National Institutes of Health (NIH publication 85-23, revised 1985).

In brief, after induction of inhalational anesthesia, the pericardium was harvested from between the phrenic nerves through a right thoracotomy incision. At this time, a transittime ultrasonic flow probe (A-Series; Transonic Systems, Inc, Ithaca, NY) was placed around the ascending aorta to measure blood flow at that point. The connecting portion of the probe was tunnelled to the mid-dorsal subcutaneous tissue. Next, the left latissimus dorsi muscle was mobilized from the chest wall through a separate flank incision, leaving its humeral insertion intact. A bipolar nerve lead (Medtronic, Inc, Minneapolis, Minn) was placed around the thoracodorsal nerve. The lead was connected to a neurostimulator (Itrel model 7421; Medtronic, Inc), which was placed in the left rectus sheath. The autogenous, fresh pericardium was wrapped around a cylindrical polypropylene mandrel (diameter $3.4 \mathrm{~cm}$, volume $2.5 \mathrm{~mL} / \mathrm{kg}$ ) and secured at the base with $5-0$ polypropylene suture to a ring of Dacron felt (USCI, Billerica, Mass). The latissimus muscle was then wrapped circumferentially around the pericardium-lined mandrel from 1.5 to 2 times. The muscle was secured to the sewing ring with polypropylene sutures, and the SMV layers were tacked together with superficially placed polyglactin acid sutures. The wounds were closed in layers with absorbable polyglactin acid sutures.
All animals underwent a 3-week period of vascular delay from the time of SMV construction before conditioning. The neurostimulator was then activated to deliver a $2-\mathrm{Hz}$ single pulse of 1 - to 1.5 -volt amplitude and $210-\mu$ s duration for a period of 6 weeks. This has been shown to induce transformation of the muscle fiber histologic condition from fasttwitch, fatiguable to slow-twitch, fatigue-resistant fibers. ${ }^{8}$

Connection to the circulation. The configuration of the SMV in relation to its connection to the circulation and the sites of pressure and flow sensors are depicted in Fig 1. After the conditioning process was complete, the dogs were reanesthetized and the SMV mandrel was removed. The left side of the chest was entered through the fourth intercostal space. A specially constructed valved conduit consisting of a combination of a ringed polytetrafluoroethylene graft ${ }^{*}$ (12 $\mathrm{mm}$ ) with an interposed porcine valved Dacron conduit (12 $\mathrm{mm}$, Hancock; Medtronic, Inc) was anastomosed end to side to the descending thoracic aorta. The proximal portion of this conduit was connected to a base-cap of polytetrafluoroethylene cardiovascular patch, which was anastomosed to the SMV. A 10-mm ventriculotome was then used to excise a cylindrical portion of the LV apex. A second specially constructed $12-\mathrm{mm}$ valved conduit, also connected to the SMV base cap, was then anastomosed without cardiopulmonary bypass to the ventricular apex with a right-

*Gore-Tex graft, registered trade name of WL Gore \& Associates, Inc, Flagstaff, Ariz. 


\section{Connection to Circulation Off to ON, at Chronic Setting: $33 \mathrm{~Hz}$}

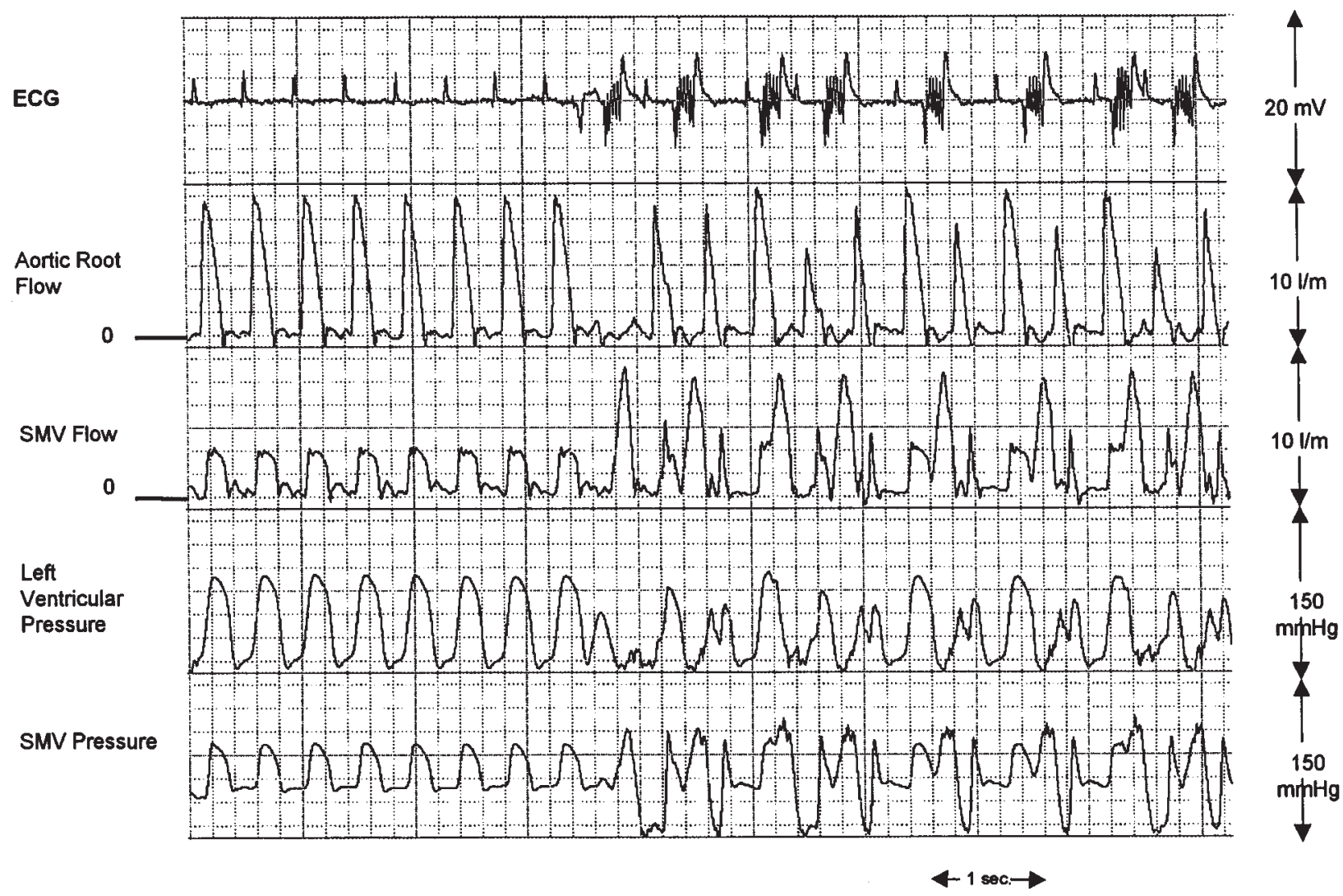

Fig 2A. Pressure recordings made at the time of connection of the SMV to the systemic circulation. Transition from the control state with the SMV OFF to stimulation at $33 \mathrm{~Hz}, 1: 2$, can be seen, with corresponding changes in the flow and pressure tracings.

angled plastic connector (Medtronic, Inc). The connector was secured to the ventricular apex with interrupted, 2-0 pledget-supported polyester sutures. An epicardial sensing electrode (model 6917; Medtronic, Inc) was attached on the left ventricle. The grafts were de-aired, and the nerve stimulator was replaced with a synchronized pulse-train cardiomyostimulator (SP1005; Medtronic, Inc). The stimulator was programmed to deliver a $33-\mathrm{Hz}$ burst train stimulus (each pulse of $210 \mu$ s duration), with a delay of 225 to $250 \mathrm{~ms}$ from the $\mathrm{R}$ wave and a burst train duration of $240 \mathrm{~ms}$. The descending thoracic aorta just distal to the left subclavian artery, but proximal to the aortic anastomosis, was then narrowed approximately $50 \%$ with umbilical tape to increase passive flow from the left ventricle through the SMV circuit during cardiac systole. After partial aortic ligation, total cardiac output and LV pressure remained the same; but passive flow through the SMV, which had been minimal, increased to $15 \%$ to $35 \%$ of the total systemic output.

No attempt was made to prevent thrombosis with heparin or warfarin. The dogs were given $85 \mathrm{mg}$ of aspirin orally every day as their only anticoagulant.
Hemodynamic measurements. Initial hemodynamic measurements were made after the SMV was connected to the circulation. In addition to the aortic flow probe that was placed at the time of SMV construction, a second ultrasonic flow probe was placed around the efferent conduit from the SMV. Polyurethane catheters $(2.5 \mathrm{~F})$ were inserted into the left ventricle, the SMV, and the carotid artery and connected to implantable subcutaneous ports (Vascular-Access Ports; Vascular Access Technologies, Skokie, Ill). They were used for pressure monitoring with fluid-filled tubing connected to transducers. A temporary cannula for pressure monitoring was placed in the femoral artery. Measurements were made not only with the stimulator OFF and $\mathrm{ON}$ at the chronic setting of $33 \mathrm{~Hz}$, mode 2 , but also at $33-\mathrm{Hz}$ and $50-\mathrm{Hz}$ burst stimulation with the cardiomyostimulator set at both mode 1 (heart rate to SMV ratio 1:1 when heart rate is less than 120 beats/min; 1:2 when greater than 120 beats/min) and mode 2 (ratio 1:2, heart rate less than 120 beats/min; 1:3 when greater than 120 beats/min). The varying burst frequencies and contraction ratios were tested to show the potential for skeletal muscle to provide increased assistance at these more intense 


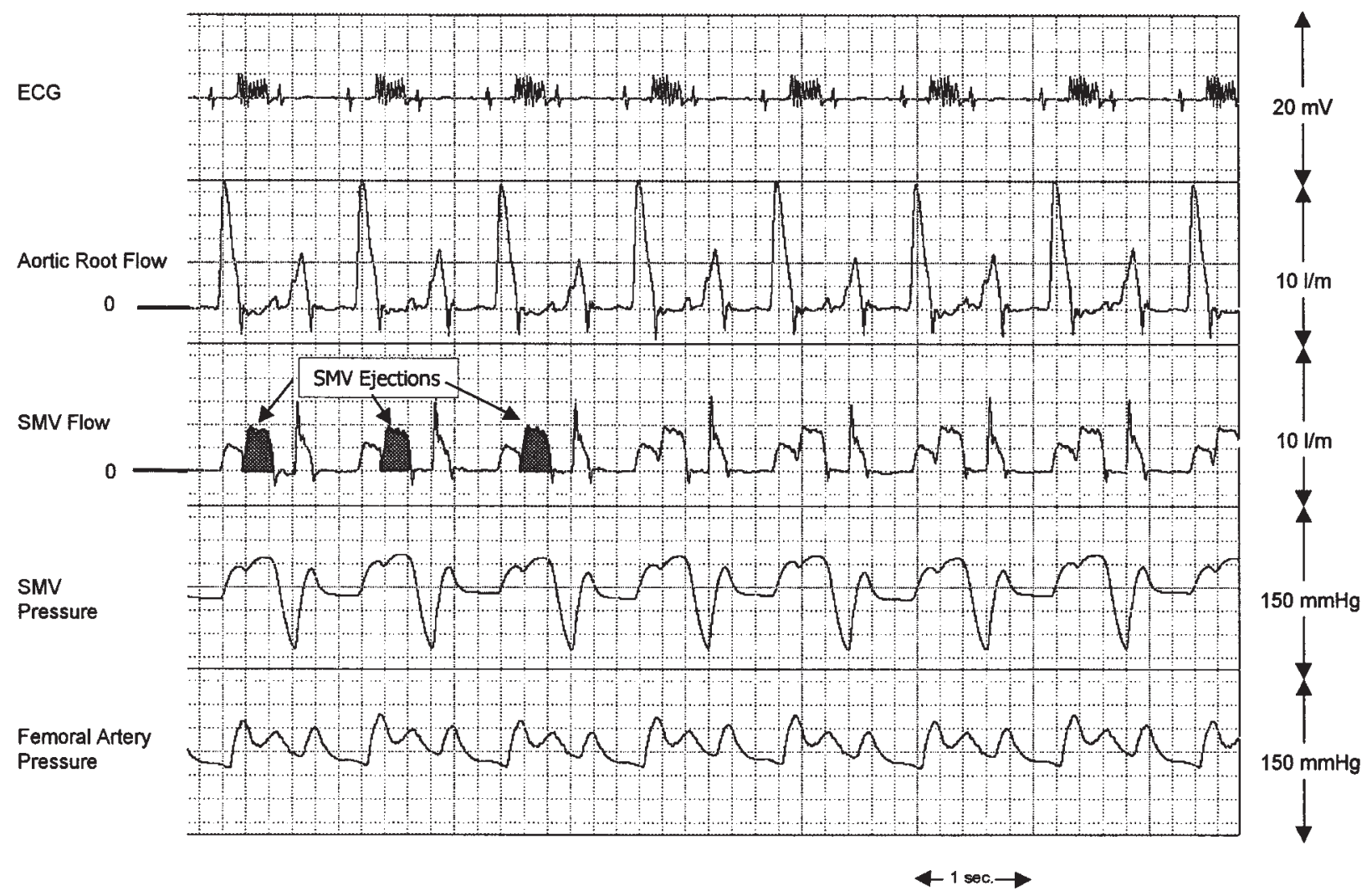

Fig 2B. The SMV is seen contracting at $33 \mathrm{~Hz}$ at a 1:2 ratio (the chronic stimulation setting) with the heart; shaded areas in the SMV flow trace indicate SMV stroke volume.

stimulation parameters. Data were collected as hardcopy on a Gould ES 1000B recording and display system (Gould Instruments Systems, Valleyview, Ohio) and digitally on a computer utilizing a data acquisition and analysis program (Windaq; Dataq Instruments, Akron, Ohio). The sampling rate was $400 \mathrm{~Hz}$. The incision was then closed in layers, and the flow probes and 3 pressure monitoring ports were left near the mid-dorsal area of the animals' subcutaneous tissue. The cardiomyostimulator was placed beneath the rectus sheath. The stimulator was set chronically to contract in mode 2 , with a 225 - to $250-\mathrm{ms}$ delay and $240-\mathrm{ms}$ duration at $33-\mathrm{Hz}$ burst frequency.

Chronic hemodynamic measurements. The animals were allowed to recover after the SMVs were placed in circulation. The pressure monitoring ports were flushed 2 to 3 times weekly to maintain patency with a $500-$ unit/mL concentration of sodium heparin. Hemodynamic measurements on each animal were then performed at 1 and 2 weeks and 1, 2, and 3 months and roughly every 2 to 3 months thereafter, unless a change in the animal's condition occurred. During a subsequent pressure recording at 2 to 3 months in 4 of the animals, a continuous infusion of intravenous propranolol was given at
$1 \mathrm{mg} / \mathrm{kg}$ per minute for 1 hour after a $10-\mathrm{mg} / \mathrm{kg}$ bolus dose to induce a low cardiac output state, defined as a decrease in aortic blood flow of $50 \%$ from control. In 1 dog the infusion was discontinued because of a sudden, precipitous fall in blood pressure. In the remaining $3 \mathrm{dogs}$, data under low output conditions were recorded after 1 hour of continuous propranolol infusion.

Data analysis. Hemodynamic recordings were analyzed on a computer using the data acquisition and analysis program (Windaq; Dataq Instruments, Inc). Data were analyzed for each setting for a minimum of 10 SMV beats (total heartbeats 10 to 30 , depending on contraction ratio).

Stroke volumes for both the SMV and the left ventricle were determined by integrating the area underneath the SMV and aortic flow traces. SMV stroke volume was defined as the stroke volume only during SMV ejection (Fig 2B). To calculate the work done by the left ventricle pumping blood through the SMV circuit versus work done by the SMV itself, the flow through the SMV when the SMV was contracting was divided into active and passive components. Passive $S M V$ flow was defined as all the flow through the SMV during the cardiac cycle except for SMV ejection. This definition 


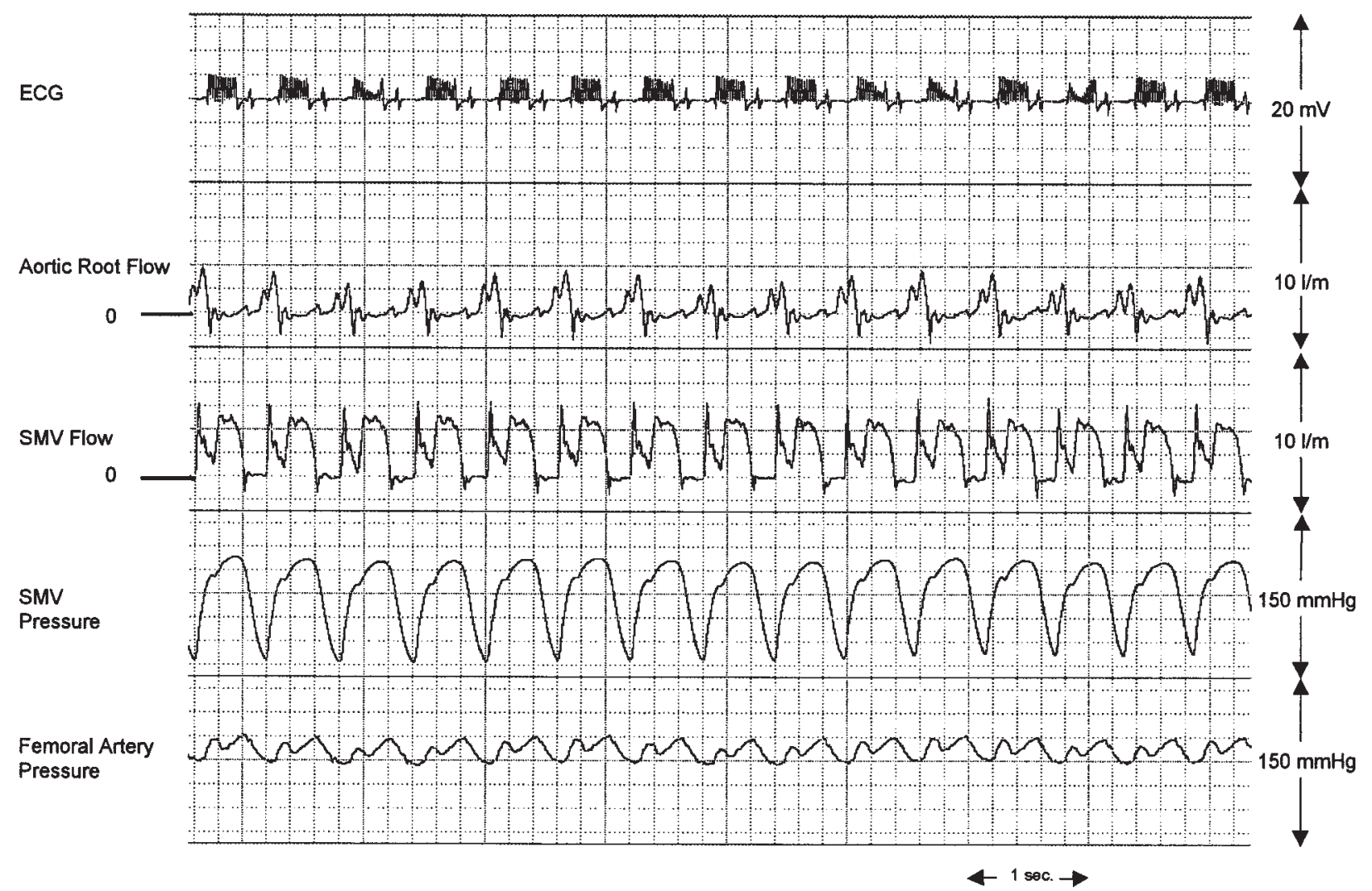

Fig 2C. Pressure recording made after 248 days of pumping blood continuously in the circulation. The SMV is shown contracting at $50 \mathrm{~Hz}, 1: 1$ ratio.

of passive SMV flow assumes that passive flow is independent of SMV relaxation and likely underestimates the contribution that SMV relaxation adds to the flow through SMV circuit and ascribes it to the left ventricle instead. $L V$ stroke volume was defined as the sum of flow across the aortic valve plus passive SMV flow for a cardiac cycle.

The LV and SMV tension time indices were calculated by integrating the pressure measurements collected from within each respective ventricle (cardiac or skeletal muscle) during their respective systolic contractions. Stroke work was defined for both the left ventricle and the SMV as the product of the ejected stroke volume (including passive flow through the SMV as part of LV stroke volume) and the mean pressure in the ventricle during its systole. Power output was calculated as the product of stroke work and the number of contractions per minute of the respective ventricle. Data are expressed as mean \pm SD. Statistical analysis was performed with SPSS for Windows (SPSS Inc, Chicago, Ill), with an analysis of variance for repeated measures with a Helmert contrast to test for differences for the hemodynamic parameters between the SMV OFF state and during stimulation at $33 \mathrm{~Hz}$ and $50 \mathrm{~Hz}$ and between $33-\mathrm{Hz}$ and $50-\mathrm{Hz}$ stimulation.

\section{Results}

Initial hemodynamic data. Data obtained at time of connection of the SMV to the circulation are presented in Tables I and II. The decrease in LV end-diastolic pressure with the pacemaker ON versus OFF, although statistically significant, was only $0.7 \mathrm{~mm} \mathrm{Hg}$ at $33 \mathrm{~Hz}$ and $1.2 \mathrm{~mm} \mathrm{Hg}$ at $50 \mathrm{~Hz}$. At the chronic stimulation frequency of $33 \mathrm{~Hz}, 1: 2$ contraction ratio with the heart, LV peak systolic pressure decreased in the beat following SMV contraction by $19 \%$ at $33 \mathrm{~Hz}$ and by $22 \%$ at $50 \mathrm{~Hz}$. Diastolic blood pressure measured in the SMV during SMV contraction was augmented 36\% when compared with the mean diastolic blood pressure with the SMV OFF. At $50 \mathrm{~Hz}$ burst frequency, 1:2 ratio, the diastolic augmentation was $50 \%$. During SMV relaxation, the diastolic pressure in the SMV decreased by $60 \%$ when compared with the diastolic pressure on unstimulated beats.

During SMV-cardiac assistance at a 1:2 ratio, a significant portion of the flow through the left ventricle 
Table I. Initial measured hemodynamic data averaged for all 10 dogs

\begin{tabular}{|c|c|c|c|c|c|c|c|c|}
\hline & \multicolumn{2}{|c|}{ OFF } & \multicolumn{2}{|c|}{ ON at $33 \mathrm{~Hz}$} & \multicolumn{2}{|c|}{ ON at $50 \mathrm{~Hz}$} & \multirow{2}{*}{$\begin{array}{c}\text { OFF vs ON } \\
\text { (P value) }\end{array}$} & \multirow{2}{*}{$\begin{array}{c}33 \mathrm{~Hz} \text { vs } 50 \mathrm{~Hz} \\
\text { (P value) }\end{array}$} \\
\hline & Mean & $S D$ & Mean & $S D$ & Mean & $S D$ & & \\
\hline Heart rate & 132 & 13 & 133 & 16 & 135 & 15 & NS & NS \\
\hline mFAP & 67.1 & 8.9 & 66.1 & 9.0 & 63.5 & 15.0 & NS & NS \\
\hline mCarotid & 72.7 & 6.2 & 72.1 & 8.4 & 72.7 & 7.4 & NS & NS \\
\hline LVEDP & 13.1 & 5.2 & 12.4 & 5.1 & 11.9 & 5.4 & .012 & NS \\
\hline LVSys & 90.9 & 9.9 & 74.1 & 15.9 & 71.3 & 14.2 & $<.01$ & NS \\
\hline Peak SMVP & $*$ & $*$ & 81.5 & 17.1 & 89.5 & 19.9 & $*$ & NS \\
\hline SMV Dia & 59.8 & 7.9 & 24.5 & 16.4 & 25.6 & 12.2 & $<.01$ & NS \\
\hline mAoQ & 2427 & 534 & 1847 & 515 & 1744 & 486 & $<.01$ & .027 \\
\hline mSMVQ & 648 & 294 & 1218 & 409 & 1316 & 528 & $<.01$ & NS \\
\hline Total Q & 3075 & 631 & 3065 & 490 & 3060 & 474 & NS & NS \\
\hline LVSVAo & 20.0 & 6.0 & 12.0 & 5.0 & 11.0 & 4.9 & $<.01$ & NS \\
\hline Passive SMVSV & 5.2 & 2.0 & 2.8 & 1.5 & 1.9 & 1.1 & $<.01$ & $<.01$ \\
\hline SMVSV & $*$ & $*$ & 10.3 & 4.2 & 13.6 & 4.9 & $*$ & $<.01$ \\
\hline
\end{tabular}

mFAP, Mean femoral artery pressure; $m$ Carotid, mean carotid artery pressure; LVEDP, LV end-diastolic pressure; LVSys, peak LV systolic pressure; peak SMVP, peak pressure during SMV contraction; $S M V$ Dia, diastolic pressure inside the SMV; $m A o Q$, mean flow across the ascending aorta; $m S M V Q$, mean flow through the SMV; total Q, sum of mAoQ + SMVQ; LVSVAo, portion of left ventricular stroke volume ejected through the aortic valve; Passive SMVSV, portion of stroke volume through the SMV caused by LV ejection; SMVSV, stroke volume from the SMV during SMV contraction.

*Data not obtainable.

$P$ values were determined with analysis of variance.

Table II. Initial derived hemodynamic parameters averaged from all 10 dogs

\begin{tabular}{|c|c|c|c|c|c|c|c|c|}
\hline & \multicolumn{2}{|c|}{$O F F$} & \multicolumn{2}{|c|}{ ON at $33 \mathrm{~Hz}$} & \multicolumn{2}{|c|}{$O N$ at $50 \mathrm{~Hz}$} & \multirow{2}{*}{$\begin{array}{c}\text { OFF vs } O N \\
(\mathrm{P} \text { value })\end{array}$} & \multirow{2}{*}{$\begin{array}{c}33 \mathrm{~Hz} \text { vs } 50 \mathrm{~Hz} \\
\text { (P value) }\end{array}$} \\
\hline & Mean & $S D$ & Mean & $S D$ & Mean & $S D$ & & \\
\hline LVTTI & 14 & 3 & 10 & 4 & 9 & 4 & $<.01$ & NS \\
\hline SMV TTI & $*$ & $*$ & 18 & 4 & 25 & 9 & $*$ & $<.01$ \\
\hline LVSW & 1601 & 694 & 707 & 535 & 558 & 476 & $<.01$ & $<.01$ \\
\hline LVSWI & 2319 & 959 & 1026 & 771 & 811 & 691 & $<.01$ & $<.01$ \\
\hline SMV SW & * & $*$ & 816 & 479 & 1517 & 946 & $*$ & $<.01$ \\
\hline SMV SWI & $*$ & * & 1191 & 677 & 2207 & 1355 & $*$ & $<.01$ \\
\hline LVMW & 205611 & 73040 & 92060 & 66539 & 74011 & 61284 & $<.01$ & $<.01$ \\
\hline LMWI & 299090 & 102355 & 134249 & 97572 & 107989 & 902212 & $<.01$ & $<.01$ \\
\hline SMV MW & $*$ & $*$ & 53865 & 31008 & 100377 & 61530 & $*$ & $<.01$ \\
\hline SMV & $*$ & $*$ & 79039 & 45447 & 147064 & 92572 & $*$ & $<.01$ \\
\hline
\end{tabular}

LVTTI, LV tension time index; SMV TTI, SMV tension time index; LVSWI, LV stroke work index; SMV SWI, SMV stroke work index; LVMWI, LV minute work index; SMVMW, SMV minute work (power output); SMVMWI, SMV minute work index.

*Data not obtainable.

$P$ values determined by analysis of variance.

was diverted from the native LV outflow tract and rerouted through the SMV. During the initial hemodynamic recordings in all 10 animals, passive SMV flow (the amount of flow being pumped by the left ventricle through the SMV circuit) averaged $26 \%$ of the total blood flow. During SMV contraction at $33 \mathrm{~Hz}, 1: 2$ ratio, the blood flow through the SMV increased such that $40 \%$ of the total systemic flow was directed through the SMV. At a burst frequency of $50 \mathrm{~Hz}, 43 \%$ of the total systemic flow went through the SMV. The measured stroke volume through the aortic valve after an SMV contraction decreased $40 \%$ and $45 \%$ at 33 and $50 \mathrm{~Hz}$, respectively. However, because of the increase in blood flow through the SMV, total systemic blood flow essentially remained the same.

The initial hemodynamic data also showed significant reductions in the LV tension time index and LV stroke work (LVSW) and minute work (LVMW) during SMV contractions. The LV tension time index decreased by $29 \%$ at $33 \mathrm{~Hz}$ and $39 \%$ at $50 \mathrm{~Hz}$. At $33 \mathrm{~Hz}$, LVSW 

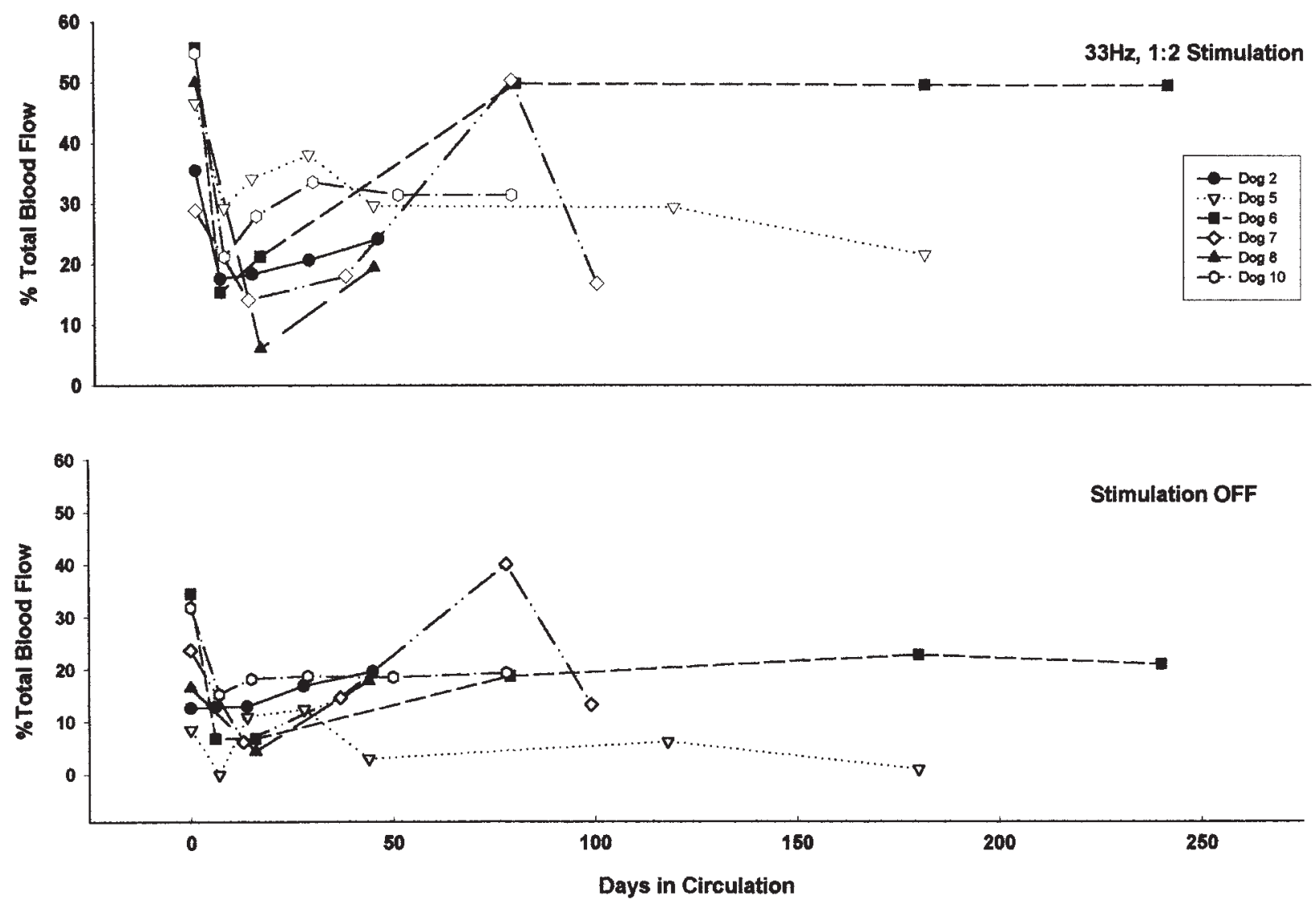

Fig 3. Blood flow through the SMV circuit at $33 \mathrm{~Hz}, 1: 2$ (combined SMV stroke volume plus passive stroke volume), versus passive flow with the SMV OFF for each of the 6 dogs that survived more than 1 month is shown for the duration of the experiment. SMV blood flow is expressed as percent of total systemic blood flow.

decreased by $56 \%$ when compared with the LVSW with the cardiomyostimulator OFF. LVSW was decreased by $65 \%$ when the SMV was stimulated at $50 \mathrm{~Hz}$. LV power output (LVMW) was decreased by $55 \%$ at $33 \mathrm{~Hz}$ and $64 \%$ at $50 \mathrm{~Hz}$. The SMV itself, when stimulated at 33 $\mathrm{Hz}$, was capable of $51 \%$ of the stroke work of the native left ventricle alone with the SMV OFF and $95 \%$ of native (unassisted) LVSW at $50-\mathrm{Hz}$ burst stimulation. When SMV stroke work (SMV SW) was compared with the assisted LVSW, SMV SW exceeded that of the assisted left ventricle: at $33 \mathrm{~Hz}$, SMV SW was $115 \%$ of LVSW and $271 \%$ of LVSW at $50 \mathrm{~Hz}$. At the chronic stimulation setting of $33 \mathrm{HZ}$ and a 1:2 ratio, SMV power output (SMVMW) was $26 \%$ of the native left ventricle and 59\% of the assisted LVMW. At the higher burst stimulation frequency of $50 \mathrm{~Hz}$, the SMV power output was $49 \%$ of the native LV power output and $136 \%$ of the assisted power output of the left ventricle.

Chronic SMV function. The SMVs were assessed over time. Fig 3 depicts both the active flow through the SMV circuit (total flow through SMV during stimulation) and the passive flow (total flow with SMV OFF) through the SMV for the 6 animals that survived 1 month and beyond, for the duration of the experiment. The data on the additional 4 dogs were similar; they were excluded only for clarity of the illustration. There is an initial drop in SMV performance, as measured by SMV flow, that is seen in the 1-week measurement after the initial connection to the circulation. However, during subsequent measurements, the flow through the SMV approaches the value obtained at the time of connection to the circulation. Once returning towards baseline, the function of the SMVs remained relatively stable over time in most dogs.

Four dogs were studied under conditions of pharmacologically induced acute cardiac failure at 2 to 3 months in circulation. In 1 of these dogs, infusion of propranolol resulted in rapid and profound hemodynamic collapse; although the animal was allowed to recover, these data were excluded from the analysis. In 


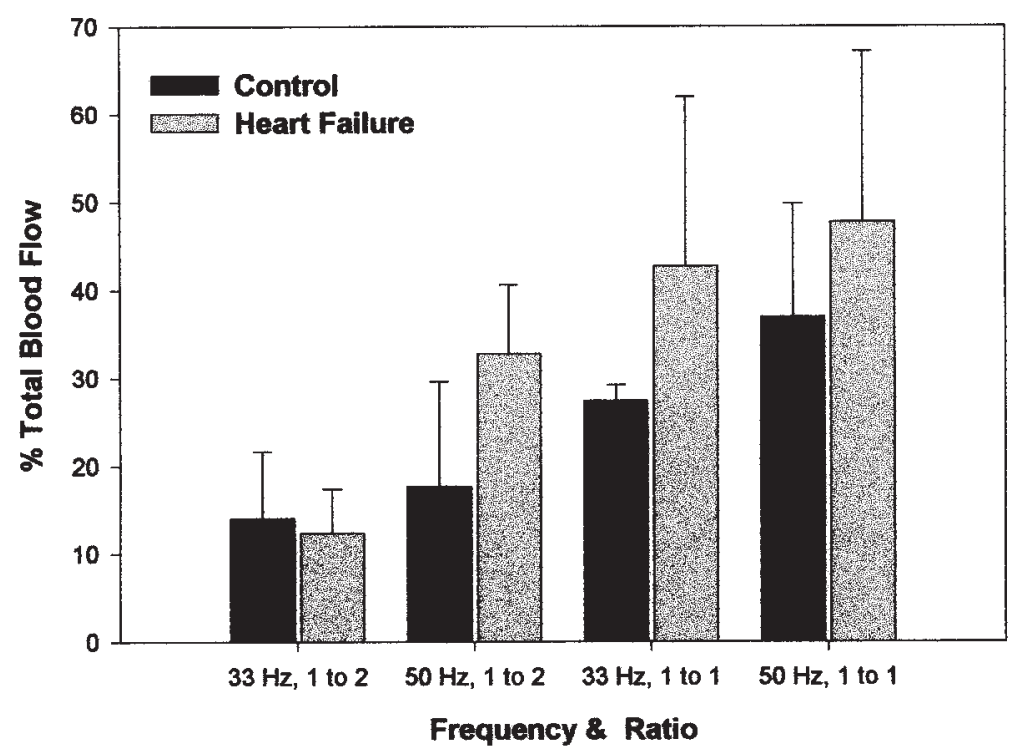

Fig 4. SMV blood flow, expressed as percentage of total systemic flow, at varying burst frequencies and contraction ratios before induction of heart failure with propranolol (control; solid bars) and after inducing failure with propranolol (heart failure; shaded bars).

the 3 remaining dogs, cardiac output was decreased by $50 \%$ of control for 1 hour, and SMV performance was assessed before and after propranolol infusion (Fig 4). During heart failure, there was no statistical difference in the percentage of total blood flow through the SMV circuit before propranolol infusion when compared with that during propanolol infusion. The percentage of total systemic output flowing through the SMV fell minimally at $33 \mathrm{~Hz}, 1: 2$; however, it showed a definite trend toward increasing under failure conditions at 50 $\mathrm{Hz}, 1: 2$, and both 33 and $50 \mathrm{~Hz}$ at a $1: 1$ contraction ratio. When expressed as a percentage of native $\mathrm{LV}$ work or power, neither stroke work or power output of the SMV changed significantly between the control and heart failure states. Pressure tracings from 1 animal before and after induction of a low-output state at different contraction ratios are shown in Fig 5.

The fate of each of the 10 dogs with LV apex-to-aorta configured SMVs is shown in Table III. One dog was alive 228 days (as of July 7, 1998); the remaining dogs survived 7 to 249 days with SMVs pumping blood in circulation. Of the dogs that died, 6 deaths, including the initial 4 dogs, were for reasons not directly related to the function of the SMV in the circulation. Technical factors in placing the SMVs in circulation or during subsequent measurements were directly related to the deaths of these first 4 animals. This likely represents a learning curve for the development of this model. One dog died of unexplained spontaneous retroperitoneal bleeding, and $1 \mathrm{dog}$ died of an infection at the cardiomyostimulator site. Three dogs died of thromboembolic complications, presumably from the SMV. However, presence of thrombus in the SMV was detected in only $1 \mathrm{dog}$.

One animal in this series survived 8 months in circulation. Pressure and flow traces from implantation and at day 248 are presented in Fig 2. The flow and pressure traces were similar throughout the time that this animal's SMV was in circulation. The distribution of total blood flow compared between stimulator OFF and $\mathrm{ON}$ at $33 \mathrm{~Hz}, 1: 2$ (chronic setting), is depicted in Fig 6. Initially, flow through the SMV with the stimulator at $33 \mathrm{~Hz}, 1: 2$, was greater than flow through the native LV outflow tract. At the interval 2-week recording, there was a substantial dip in SMV flow that stabilized at the 3-month recording; from that time, the flow through the SMV and through the aortic valve each comprised approximately one half of the total systemic output.

Fig 7 depicts the stroke work of the SMV and left ventricle over time for this animal. SMV SW at $33 \mathrm{~Hz}$ was about equal to that of the native left ventricle (with the stimulator OFF). SMV SW was about 1.5 to 3 times that of the assisted left ventricle throughout the study, with the exception of the measurement at 8 months. At $50 \mathrm{~Hz}$, the stroke work of the SMV decreased below that of the native left ventricle at 2 weeks but otherwise 


\section{Day 78: Acute Heart Failure}

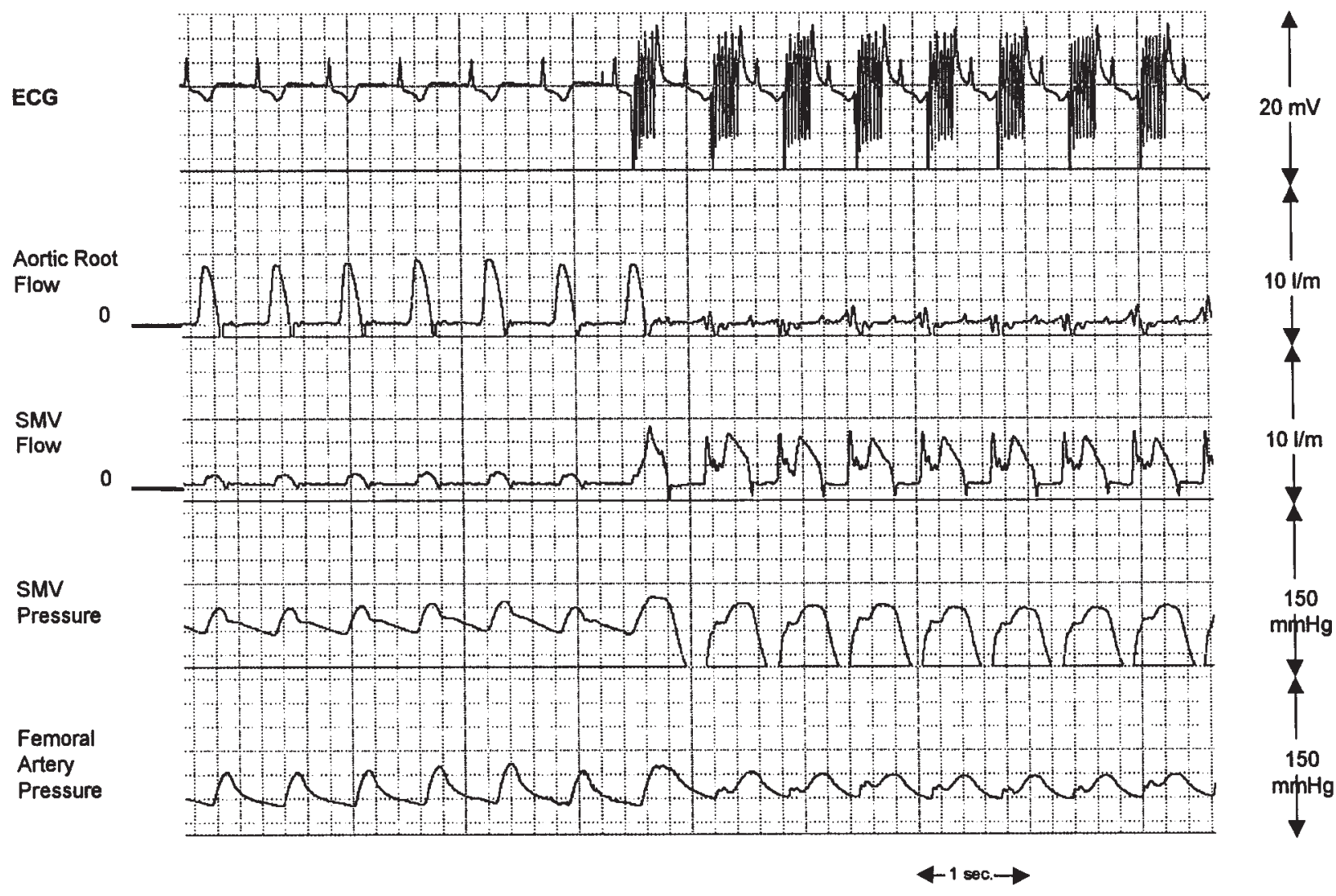

Fig 5. Pressure tracings taken from 1 animal at the time of a low-output study after 78 days in circulation. The pressure recording after 1 hour of continuous low cardiac output was induced by propranolol infusion. The transition from temporarily inhibiting the SMV "OFF" to contraction at $33 \mathrm{~Hz}, 1: 1$, is shown. At this setting, almost the entire total systemic output is flowing through the SMV.

remained superior to that of the native left ventricle. Stroke work at $50 \mathrm{~Hz}$ remained 2 to 3 times that of the assisted ventricle. Under both burst frequencies, LVSW decreased dramatically with the SMV ON compared with the SMV OFF.

Power output of the left ventricle and SMV was also calculated over time for the longest surviving animal at both 33 and $50 \mathrm{~Hz}$, for 1:2 and 1:1 assist ratios (Fig 8). Power output of the SMV at $33 \mathrm{~Hz}, 1: 2$, was comparable to the assisted left ventricle. It remained stable from 3 to 8 months after the SMV was placed into circulation. Power output at $50 \mathrm{~Hz}, 1: 2$, was also comparable to that of the assisted ventricle and remained relatively stable throughout the study period. At a 1:1 ratio with the heart, SMV power exceeded that of the native, unassisted left ventricle by $42 \%$ at $33 \mathrm{~Hz}$ and $29 \%$ at $50 \mathrm{~Hz}$. Over time, the SMV power output decreased both in absolute numbers and in comparison with the
Table III. Number of days in circulation and cause of death for the entire series of 10 dogs

\begin{tabular}{|c|c|c|}
\hline Dog No. & $\begin{array}{l}\text { Days in } \\
\text { circulation }\end{array}$ & Cause of death \\
\hline 1 & 17 & $\begin{array}{l}\text { Bleeding from arterial pressure monitoring } \\
\text { site }\end{array}$ \\
\hline 2 & 72 & Electively sacrificed \\
\hline 3 & 11 & Incompetent valves; clot in conduit \\
\hline 4 & 7 & Retained muscle plug from left ventricle \\
\hline 5 & 214 & $\begin{array}{l}\text { Embolism to iliac bifurcation; no clot in } \\
\text { SMV }\end{array}$ \\
\hline 6 & 249 & Spontaneous retroperitoneal hematoma \\
\hline 7 & 228 & Alive as of July 7, 1998 \\
\hline 8 & 115 & $\begin{array}{l}\text { Incompetent valve at second measurement; } \\
\text { clot in SMV with embolism to iliac } \\
\text { bifurcation }\end{array}$ \\
\hline 9 & 16 & Postoperative infection \\
\hline 10 & 99 & $\begin{array}{l}\text { Renal failure with microemboli to kidneys; } \\
\text { no clot in SMV }\end{array}$ \\
\hline
\end{tabular}


SMV OFF

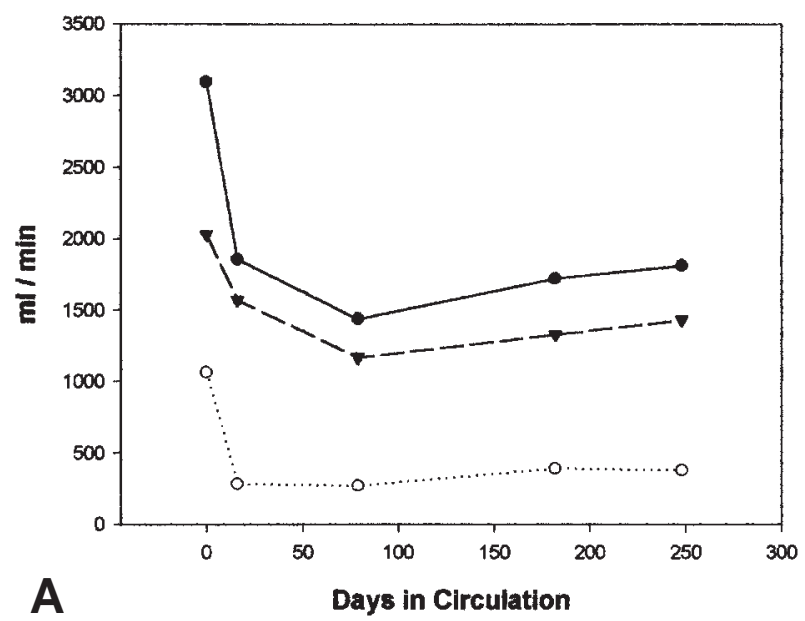

$33 \mathrm{~Hz}, 1: 2$

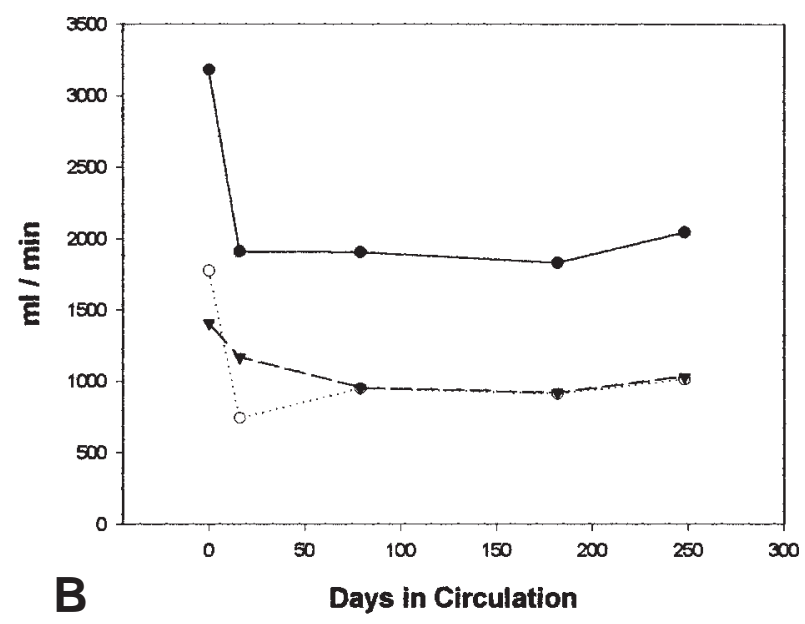

\section{$\rightarrow$ Total Systemic Blood Flow SMV Circuit Blood Flow $\rightarrow-$ Aortic Root Blood Flow}

Fig 6. Flow measured through the SMV and ascending aorta in 1 animal at several points over time. A, A depiction of the flow with the SMV OFF. There is minimal passive flow through the SMV. B, A depiction of the flow with the SMV contracting at $33 \mathrm{~Hz}, 1: 2$. From 78 days in circulation onward, the SMV flow is equal to the flow across the aortic valve. Total blood flow, sum of aortic flow and SMV flow.

LV power output at the 1:1 ratio, although SMV power output remained greater than or about equal to the minute work generated by the unassisted left ventricle.

\section{Discussion}

This study demonstrates that SMVs in a LV apex to aorta configuration can function effectively in the circulation. Maintenance of significant power output was confirmed in 1 animal at the 8-month follow-up. SMVs significantly unloaded the left ventricle, resulting in decreases in the LV peak pressure, LV end-diastolic pressure, the LV tension-time index, and LV stroke and minute work. During SMV contraction, flow was redirected from the LV outflow tract across the aortic valve through the SMV. Total systemic flow did not change significantly. To determine whether the redistribution of flow dynamics caused by the $50 \%$ constriction of the aorta would compromise cerebral circulation during SMV contraction, a flow probe was placed around the carotid artery in 1 animal during a measurement session. During SMV stimulation at 33 and $50 \mathrm{~Hz}$, mean carotid flow was $97.1 \%$ and $97.4 \%$ of control flow with the SMV OFF.
In previous acute studies of SMVs, power output, when measured with a mock circulation device, was intermediate between the stroke work of the right and left ventricles. ${ }^{9}$ In these previous studies, power output of the SMVs was equivalent to that of the right ventricle because of the slower SMV contraction rate but did not approach that of the left ventricle. In the present study, the SMVs were able to generate stroke work varying from approximately one half that of the unassisted left ventricle at a $33-\mathrm{Hz}$ burst frequency stimulation and a 1:2 contraction ratio, to nearly equal to the unassisted LV at $50 \mathrm{~Hz}, 1: 2$. While pumping at only one half the rate of the heart rate, the power output of the SMVs was $36 \%$ and $45 \%$ of unassisted LVMW at 33 and $50 \mathrm{~Hz}$. Power output of the SMVs stimulated at a 1:2 contraction ratio with the heart was maintained over time.

Because the SMVs were preloaded by LV contraction, our use of mean SMV pressure during ejection to determine SMV SW without taking LV preloading into consideration would likely overestimate SMV SW and thereby SMV power output. At the same time, an assumption that SMV relaxation plays no role in deter- 
$33 \mathrm{~Hz}, 1: 2$ Ratio

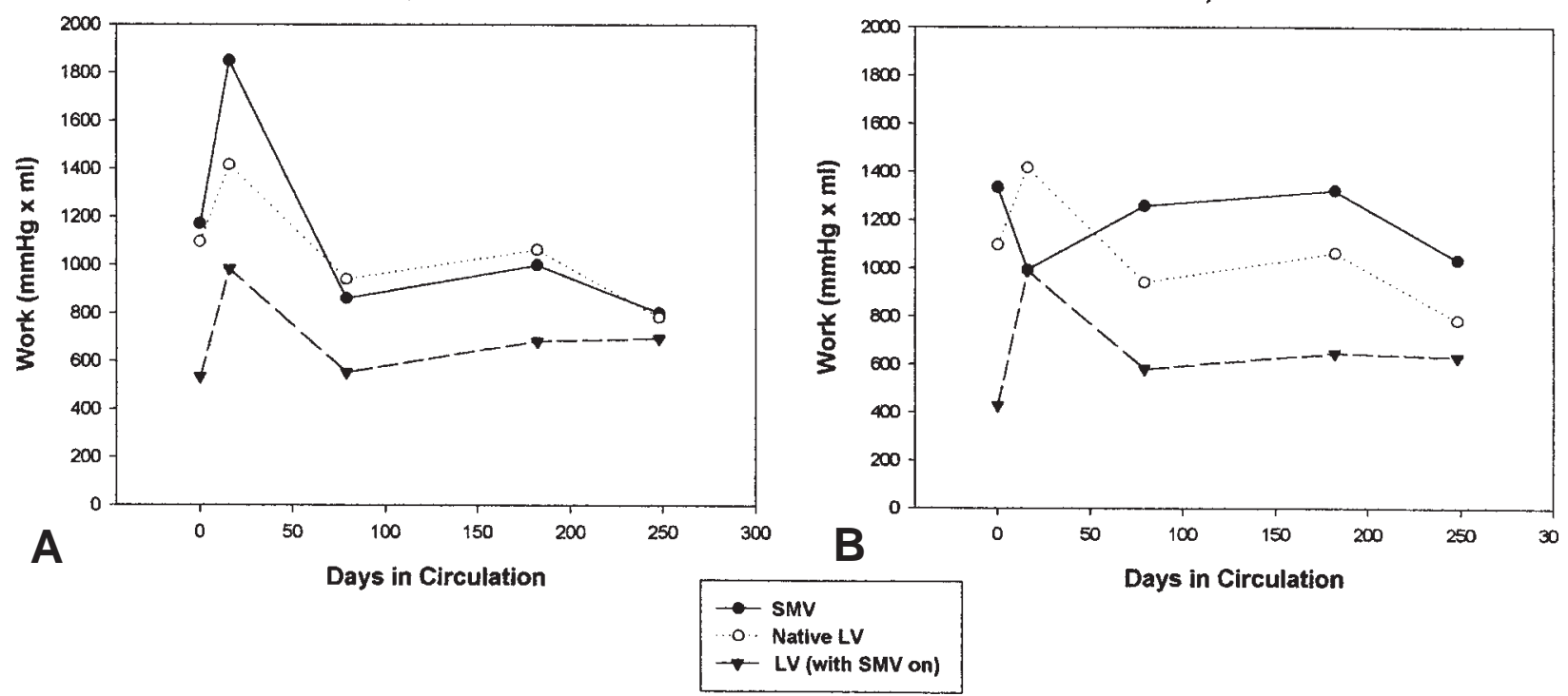

Fig 7. Stroke work in the SMV, the native left ventricle (with the SMV OFF), and the left ventricle during SMV contraction at $33 \mathrm{~Hz}, 1: 2$ (A) and $50 \mathrm{~Hz}, 1: 2$ (B), measured in 1 animal over time. At $33 \mathrm{~Hz}$, SMV SW was equivalent to that of the native left ventricle. At $50 \mathrm{~Hz}$, SMV SW generally exceed that of the native left ventricle.

mining preload and passive flow through the SMV during assist may have underestimated SMV stroke volume and thereby underestimated SMV SW and power output. Clearly, further studies are needed to determine "true" stroke work of the SMV; a conductance catheter and other methods to derive pressure-volume loops from the SMV will help us more accurately determine stroke work and power output.

Some earlier studies on the feasibility of skeletal muscle for cardiac assist used a left ventricle-to-aorta model. Stevens and colleagues ${ }^{10,11}$ performed acute studies with an unconditioned rectus muscle and demonstrated, before muscle fatigue occurred, skeletalmuscle assist increased total cardiac output during $\beta$ blockade-induced heart failure. Brister and coworkers, ${ }^{12}$ in an acute study, used a similar model, but with a single valve in the afferent position. The LV apex-to-aorta connection has been evaluated in a computer model by Platt and colleagues, ${ }^{13}$ who determined it to be the most efficient form of ventricular assist.

In our previous attempts to establish the LV apex-to-aorta configuration as a chronic model, we initially had early thrombosis of the SMV circuit. ${ }^{14}$ In this previous study, flow through the SMV was dependent on SMV contraction; with chronic stimulation at a 1:2 ratio with the heart, stagnation of blood flow inside the SMV secondary to the lower contraction rate may have encouraged thrombus formation. To promote continuous passive flow through the SMV, a constriction of the aorta proximal to the SMV-aortic anastomosis was created. ${ }^{6}$ One dog in this previous series survived 76 days, being killed at that time because of an infected indwelling flow probe. The remaining 4 dogs lived only up to 2 weeks, dying of rupture of the SMV or the aortic anastomosis and erosion of a flow probe into the great vessels. We were previously able to develop a chronic model of SMV aortic counterpulsation with pericardium-lined SMVs; pericardium-lined SMVs did not rupture and appeared to exhibit thromboresistance. ${ }^{7}$ Therefore the present study incorporated the use of autogenous pericardium to line the SMVs and the presence of an aortic constriction to create passive SMV flow.

We have used a propranolol infusion to simulate low cardiac output in a previous study. ${ }^{7}$ In the previous study, during profound low cardiac output, SMV function, measured as percent augmentation of diastolic blood pressure, improved under heart failure conditions when compared with control. The propranolol infusion did not seem to significantly affect SMV performance. Because of our past experience with this model of heart failure, we used propranolol to simulate severe cardiac dysfunction. In our past experience with this heart failure model, animals that underwent a propranolol study at 2 weeks after the SMV was placed in circulation experienced a high mortality. ${ }^{7}$ In fact, in this current study, 1 animal's infusion had to be terminated because 
$33 \mathrm{~Hz}, 1: 2$ Ratio

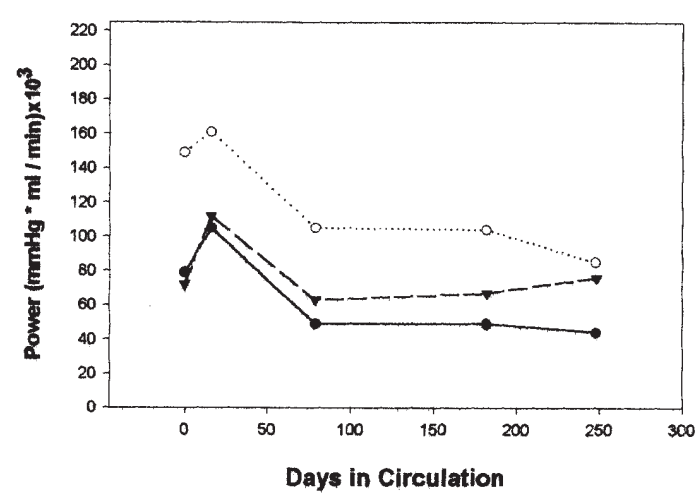

$33 \mathrm{~Hz}, 1: 1$ Ratio

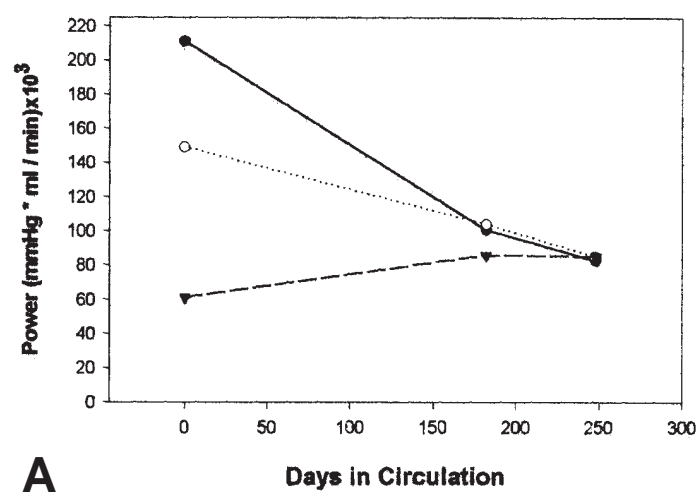

$50 \mathrm{~Hz}, 1: 2$ Ratio

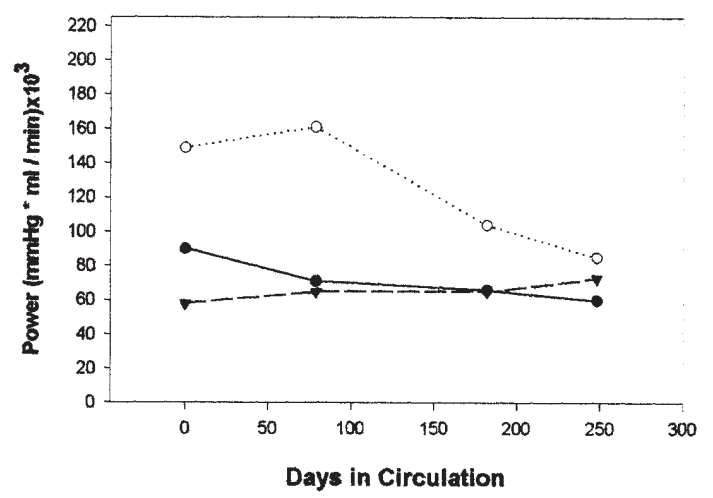

$50 \mathrm{~Hz}, 1: 1$ Ratio

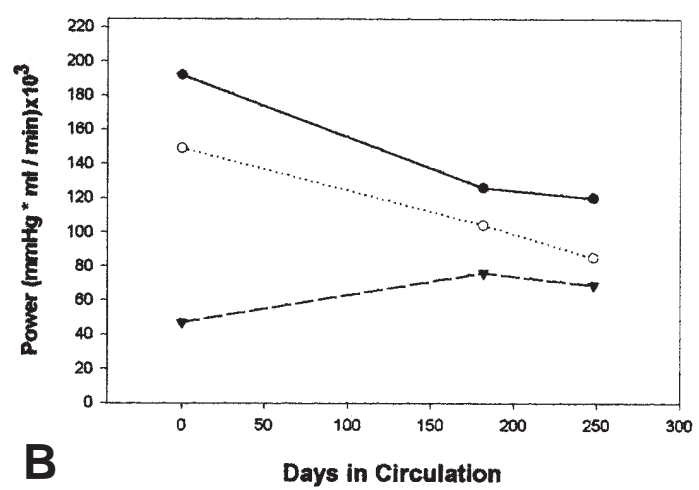

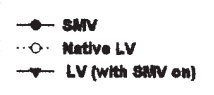

Fig 8. Power output of SMV, native left ventricle (with SMV OFF) and left ventricle during SMV assist at 4 combinations of burst frequency and contraction ratio for 1 animal over time. A, At a 1:2 ratio, SMV power output remained relatively stable. B, Power output at the 1:1 ratio was available for only the initial and 2 latest measurements.

of severe hypotension. For this study, only animals that survived up to 3 months received a propranolol infusion. Unfortunately, not all of the animals that survived this long were measured during propranolol-induced failure. There was a trend toward improvement of blood flow through the SMV compared to total systemic flow for $50 \mathrm{~Hz}, 1: 2$, and both 33 and $50 \mathrm{~Hz}$ at a 1:1 ratio. There was also an increase in the amount of total systemic flow when compared between the SMV $\mathrm{ON}$ at a 1:1 ratio and the SMV OFF. It is likely that these trends did not achieve statistical significance because of the small number of animals that underwent a propranolol study. Future studies must further define the potential for SMVs to provide assistance to a failing ventricle using this or other models of heart failure.
When examining the data over time, we noted decreases in SMV performance during the first 2 weeks after placement of the SMV into circulation. We have noted similar decreases empirically in other studies. Although electrical stimulation at $2 \mathrm{~Hz}$ has been shown to change the fiber type, it is possible that the muscle may not be fully adapted to perform chronically under loaded conditions. However, after this 2-week period, SMV flow returned toward baseline and remained stable thereafter in most dogs.

The aortic constriction was performed with the SMV pumping at the chronic stimulation parameters of 33 $\mathrm{Hz}, 1: 2$ ratio. The constrictions were adjusted to cause one third to one half of the total systemic flow to go through the SMV when the cardiomyostimulator was 
programmed at the chronic settings. Because there are 2 potential outflow tracts from the left ventricle in this model, the aortic constriction does not appreciably increase afterload when compared with the normal heart with a single LV outflow tract through the aortic valve. The aortic constriction merely redistributes a portion of blood through the alternative outflow tract to help prevent SMV thrombus formation. In reviewing the resulting passive SMV flow over time in circulation for each animal plus each animal's fate, no obvious correlation was found between absolute amount of passive flow or percent passive flow of total systemic flow and number of days in circulation with the presence or absence of clot in the SMV. Further experiments may help to determine what degree of aortic constriction, if any, is necessary for this model. Additionally, it is unknown when performed on an animal with a failing heart, whether similar aortic constrictions will result in a decreased incidence of SMV thrombi.

This study demonstrates conclusively that SMVs in an LV apex-to-aorta configuration can effectively and efficiently provide chronic cardiac assistance for up to 8 months in the circulation. Before SMVs in an LV apex-to-aorta configuration can be considered for clinical trials, further refinement is necessary to eliminate the significant attrition that occurred during this study. SMVs will also need to be tested in a chronic heart failure model. Once a reliable, low mortality model has been achieved, clinical evaluation should proceed.

We thank Elaine Hockman, $\mathrm{PhD}$, for her assistance with statistical analysis, and Janet Schofding, LVT, Lee Andrus, LVT, Cynthia Cameron, LVT, and Elizabeth Dawe, DVM, for their care of the animals used in this experiment.

\section{REFERENCES}

1. Acker MA, Anderson WA, Hammond RL, et al. Skeletal muscle ventricles in circulation: one to eleven weeks experience. J Thorac Cardiovasc Surg 1987;94:163-74.

2. Niinami H, Hooper TL, Hammond RL, et al. Skeletal muscle ventricles in the pulmonary circulation: up to sixteen weeks experience. Ann Thorac Surg 1992;53:750-7.

3. Hooper TL, Niinami H, Hammond RL, et al. Skeletal muscle ventricles as left atrial-aortic pumps: short-term studies. Ann Thorac Surg 1992;54:316-22.

4. Thomas GA, Isoda S, Hammond RL, et al. Pericardium-lined skeletal muscle ventricles: up to two years' in-circulation experience. Ann Thorac Surg 1996;62:1698-707.

5. Lu H, Fietsam R Jr, Hammond RL, et al. Skeletal muscle ventricles, configuration left ventricular apex to aorta: acute in circulation studies. Ann Thorac Surg 1993;55:78-85.

6. Greer KA, Lu H, Spanta AD, Hammond RL, Stephenson LW. Skeletal muscle ventricles, left ventricular apex-to-aorta configuration: 1 to 11 weeks in circulation. Circulation 1997;95:497-502.
7. Thomas GA, Lu H, Isoda S, et al. Pericardium-lined skeletal muscle ventricles in circulation up to 589 days. Ann Thorac Surg 1994;58:978-88.

8. Mannion JD, Bitto T, Hammond RL, Rubinstein N, Stephenson LW. Histochemical and fatigue characteristics of conditioned latissimus dorsi muscle. Circ Res 1986;58:298-304.

9. Mannion JD, Acker MA, Hammond RL, Faltemeyer W, Duckett S, Stephenson LW. Power output of skeletal muscle ventricles in circulation: short-term studies. Circulation 1987;76:155-62.

10. Stevens L, Brown J. Can noncardiac muscle provide useful cardiac assistance? Am Surg 1986;52:423-7.

11. Stevens L, Badylak SF, Janas W, Gray MH, Geddes LA, Voorhees WD III. A skeletal muscle ventricle made from rectus abdominis muscle in the dog. J Surg Res 1989;46:84-9.

12. Brister SJ, Fradet G, Dewar M, Wittnich C, Lough J, Chiu R. Transforming skeletal muscle ventricle made from the rectus abdominis muscle for myocardial assist: a feasibility study. Can J Surg 1985;4:341-4.

13. Platt KL, Moore TW, Barnea O. Performance optimization of left ventricular assistance: a computer model study. ASAIO J 1993; 39:29-38.

14. Lu H, Thomas GA, Hammond RL, et al. Intrathoracic and extrathoracic skeletal muscle ventricles in circulation: left ventricular apex to aorta configuration. J Card Surg 1994;9:332-42.

\section{Discussion}

Dr Juan C. Chachques (Paris, France). I saw in your pictures that you are still using direct nerve pacing. Do you have any problems with direct nerve stimulation? We use intramuscular electrodes because we believe that direct nerve stimulation can induce fibrosis and nerve injury.

Do you have a histologic control of the pericardium that you use inside this SMV, and what is the adaptation of the pericardium to this new function? Is this pericardium fresh or treated with glutaraldehyde?

Do you plan to use this configuration for the right heart? Perhaps for the first clinical use it would be interesting to test your SMVs for right ventricular support.

Dr Baciewicz. First, regarding muscle stimulation as compared with nerve stimulation, we have always used the nerve stimulation to stimulate the latissimus dorsi and have not had a problem. I really do not have any experience with a myostimulator.

Second, in terms of how we treat the pericardium, we simply harvest it from phrenic nerve to phrenic nerve, place it in saline solution, and then place it around the mandrel. We do not have any special treatment for it.

Third, at this point we have not used this particular model in a right ventricle situation.

Mr John H. Kennedy (Cambridge, England). I compliment you on your determination in carrying along with what is basically often a fraught project. What was the effect on baroreceptor activity in the presence of a 50\% constriction of the proximal thoracic aorta? Normally in a waveform, one would see that in an elevation of diastole, which we were not privileged to see in your slides, and, of course, that would be dependent on the synchrony in terms of radians of the pump versus the natural heart. 
Dr Baciewicz. I did not have room on the slides to show you the carotid flow tracing, but essentially it is no different from the femoral tracing.

Mr John R. Pepper (London, England). Do you have any evidence of thromboembolism inside the SMV? Did you do autopsies on the animals and look particularly at the kidneys?

Dr Baciewicz. In fact, there were several sudden deaths within 1 month in the study; but essentially in all the animals that survived long term, our problem was peripheral emboli. Two of the animals died of iliac emboli and 1 of renal failure from renal emboli. However, on all the autopsies, we did not notice any clot or thrombus in the SMV itself. Of course, there are a lot of places in this model where thrombus could develop: we have indwelling SMV catheters; there is a relative constriction in the thoracic aorta, and the animals were given only $85 \mathrm{mg}$ of aspirin per day. But that has been our downfall in terms of keeping the animal alive long term.

Dr Thierry G. Mesana (Marseille, France). It is fascinating to see a real biologic implantable device. But to be biologic means to have less thromboemboli. Do you think that your valves inside your ventricle are really necessary to assist the heart? What is the role of these valves in the thromboemboli that you saw?

Dr Baciewicz. We do think the valves are necessary. We did have earlier models where the valve conduits that we used had been sort of discards or had been on the shelf for multiple years; there was a number of emboli and thrombi on some of these valved conduits. We are now having the conduits made specifically for us; we have not noted a problem with this.

\section{Targeted}

The Journal of Thoracic and Cardiovascular Surgery gives you two tables of contents.

The condensed table of contents tells you at a glance what topics and authors are presented each month. The expanded table of contents gives you a brief abstract of each article. You select only those articles of most interest to you for further reading. 